\title{
Interdisciplinarity to Integrate Knowledge in Engineering
}

\author{
Stella Abreu ${ }^{1,3}$, Amélia Caldeira*1,3,4 ${ }^{*}$ Alexandra R. Costa ${ }^{2}$, Tiago Gomes ${ }^{2}$, Luís A. C. Roque ${ }^{1,5}$ \\ ${ }^{1}$ School of Engineering Polytechnic of Porto (ISEP-IPP), Mathematics Department,4249 - 015, Portugal \\ ${ }^{2}$ School of Engineering Polytechnic of Porto (ISEP-IPP), Planning and Management Department,4249 - 015, Portugal \\ ${ }^{3}$ LEMA - Engineering Mathematical Laboratory-ISEP, 4249 - 015, Portugal \\ ${ }^{4}$ SYSTEC-ISR - Research Center for Systems and Technologies University of Porto, 4200-464, Portugal \\ ${ }^{5}$ LIADD-INESC-TEC Campus da FEUP, 4200-465, Portugal
}

\section{A R T I C L E I N F O}

\section{Article history:}

Received: 05 April, 2017

Accepted: 22 May, 2017

Online: 16 June, 2017

Keywords:

Interdisciplinarity

soft skills

team work

mathematics teaching

working methods

\begin{abstract}
A B S T R A C T This paper is an extension of work originally presented at the $2^{\text {nd }}$ International Conference of the Portuguese Society for Engineering Education and aims to describe an interdisciplinarity teaching experiment involving three subjects of the scientific area of Mathematics and a fourth one in the area of Management. Using only one project, the students developed skills, in an integrated way, in the fields of the subjects involved. The structure of the project is described in detail. It is shown how the knowledge obtained in the different subjects is needed and how it connects together to answer the proposed challenges. We report the progress of the students' work, the main difficulties and the skills developed during this process. We conclude with a reflection on the main problems and gains that may arise in similar projects.
\end{abstract}

\section{Introduction}

This paper is an extension of work [1], originally presented at the $2^{\text {nd }}$ International Conference of the Portuguese Society for Engineering Education.

The Bologna reform aims to make the European Higher Education more comparable and compatible, unifying three different levels of study, for Bachelors, Master and Doctoral awards, across all member countries [2,3].

This reform seeks to promote the student-centred approaches and the effective implementation of more active learning practices [4].

According to these authors, the Bologna process emphasizes that efforts should be made to include learning activities with "meaning" for students, providing them additional motivation. These authors state that one of the methodologies to achieve these objectives is based on interdisciplinary project approaches [4].

This paper aims to describe an interdisciplinarity teaching experiment involving three subjects of the scientific area of

*Amélia Caldeira, Rua Dr. Bernardino de Almeida, 431, 4249-015 - Porto (Portugal), acd@isep.ipp.pt
Mathematics and a fourth one in the area of Management, in a Portuguese school of engineering.

Societal, environmental, economic, and philosophical problems are often so complex that it is impossible to fully understand them from a single perspective. Multiple viewpoints can help to solve these complex problems and challenges by converging synergistic team efforts [5].

In line with this idea, many employers recognize the need to hire graduates that are able to work as members of a team as well as being able to understand certain core disciplinary competencies and to adapt to different contexts. Because of that, in recent times the theme of interdisciplinarity has gained popularity in different circles. Despite the skepticism in some education environments, the supporters of its application to school contexts have been increasing, especially with its introduction in university curricula and research agenda $[5,6]$.

In this field, Klein, quoted by Jacobs [5], makes an important clarification of concepts, presenting a distinction between multiinter- and trans-disciplinarity that we highlight below: The multidisciplinarity is made by a juxtaposition of knowledge, 
methodologies or information from different disciplines even though the knowledge structure and the identity of the original disciplines remains unquestionable; on the other hand, interdisciplinary approaches emphasize integration and interaction, promoting the disciplinary transformation at methodological and theoretical levels; finally, in transdisciplinary approaches, research questions and practices are framed by problems arising from the life-world and studied in different points of view $[5,7]$.

"Interdisciplinarity is a means to integrate knowledge and methods in the interest of problem solving" [6]. Crossing disciplinary boundaries is particularly important for a future engineer because she/he will be called to solve complex problems. This requires not only crossing boundaries horizontally (across subjects) but also vertically (across experts, policymakers, practitioners, and the public) $[8,9,10]$.

The advantages of interdisciplinarity studies are widely accepted by teachers and researchers. Some authors refer that interdisciplinary works use the knowledge that comes from different curriculum areas that offer different perspectives on a particular problem, making the curriculum more compact and more consistent. Furthermore, interdisciplinary works provide the students with relevant, challenging and enjoyable learning experiences $[5,6]$.

Chettiparamb [6] refers that "Interdisciplinary pedagogy fosters in students a sense of self-authorship and a situated, partial and perspectival notion of knowledge that they can use to respond to complex questions, issues or problems. While it necessarily entails the cultivation of the many cognitive skills such as differentiating, reconciling, and synthesizing [...] it also involves much more, including the promotion of student's interpersonal and intrapersonal learning."

Despite this, some authors believe that collaboration is often more truly interdisciplinary in social science and humanities disciplines than in technological ones because these disciplines require that researchers work more closely to agree on methods and interpretations [11]. Notwithstanding this, interdisciplinary approaches are critical to solving the most pressing technological challenges. An evidence of this is the fact that interdisciplinary is progressively more valued by the courses' accrediting agencies [7].

In alignment with these ideas, some universities have developed some interdisciplinary design courses with the goal of improving students' abilities to operate across disciplines and improve their preparation for work [12].

This paper aims to present the results of an interdisciplinary teaching experiment performed in the Electrical Engineering Power Systems degree of the School of Engineering - Polytechnic of Porto (ISEP). The goal of this experiment was to carry out an interdisciplinary project involving four subjects of the first year of the degree, three of which from the scientific area of Mathematics - Mathematics I (MATE1), Mathematics Laboratory
I (LMAT1), Linear Algebra and Analytic Geometry (ALGAN) and one subject in the area of Management: Working Methods in Engineering (MTENG).

The subjects concerning the first semester of the first year program as well as the respective European Credit Transfer and Accumulation System (ECTS) $[13,14]$ are listed in Table I.

TABLE I. COURSE REQUIREMENTS ( $1{ }^{\text {st }}$ YEAR/ $/{ }^{\text {ST }}$ SEMESTER $)$

\begin{tabular}{|l|c|c|}
\hline \multicolumn{1}{|c|}{ SUBJECTS } & ECTS & $\begin{array}{c}\text { Contact } \\
\text { hours }\end{array}$ \\
\hline Experimental Physics & 5 & 4 \\
\hline Introduction to Electrotechnics & 6 & 4 \\
\hline Linear Algebra and Analytic Geometry & 5 & 4 \\
\hline Mathematics I & 5 & 4 \\
\hline Mathematics Laboratory I & 3 & 2 \\
\hline Working Methods in Engineering & 6 & 4 \\
\hline
\end{tabular}

Using only one project work, we intended to create the opportunity for students to develop skills, in an integrated way, in the fields of the involved subjects. Students were challenged to perform a set of tasks by applying concepts and skills developed in the four aforementioned subjects. Specific objectives were proposed for this work in each subject.

The experiment took place during twelve weeks in the first semester of the first year of the degree.

Students were assessed by three outcomes: one report, one oral presentation with discussion and a MatLab $\odot$ script. All teachers were involved in the assessment of the report and the oral presentation. The MatLab $\odot$ script was mainly assessed by the Mathematics Laboratory I (LMAT1) teacher.

Students faced initial difficulties in dealing with the interdisciplinary challenge, and with developing the soft skills required in the project. The main challenges were:

- to gain experience in team work as means to solve the interdisciplinary problems;

- to acquire insight into their own behaviour and understand how it influences collaboration in the team;

- to acquire and understand their competence and realize how it may be used for the benefit of the team.

This led to considerable gains in learning, so we will make a reflection on these gains and the benefits of carrying out a single project involving different subjects. We explore the main objectives of this interdisciplinary work, as well as the methodology and its main results.

We conclude this text with a reflection on the main lessons learned as well as with some suggestions for future interdisciplinary work involving these or other scientific areas. 


\section{The project}

Interdisciplinary projects are encouraged and very welcome in the degrees of ISEP. Using some past experiences, a group of four teachers - responsible for three subjects of the scientific area of Mathematics and a fourth one in the area of Management proposed to the students of the Electrical Engineering - Power Systems degree an interdisciplinary work.

\subsection{Organizing the project}

The purpose of this project was to give an integrated view of the several subjects of Mathematics, as well as to develop in students a number of soft skills that are pointed out as fundamental by the employers of graduated students.

In interdisciplinary research, success depends largely on the personality and attitudes of researchers. Useful characteristics are:

- curiosity about, and willingness to learn from other subjects;

- flexibility, adaptability, creativity;

- an open mind to ideas coming from other subjects and experiences;

- good communication and listening skills;

- an ability to bridge the gap between theory and practice;

- a good team worker.

The following additional abilities are very important:

- understanding (not necessarily in depth) across the project's main subject domains;

- understanding application areas, namely, Electrical Engineering, for project outcomes;

- respect for other subjects and some understanding of their general principles;

- focus on practical results, to overcome differences among subjects.

These abilities are highly relevant to achieve a good project management.

In addition to this, specific objectives were proposed in each subject.

In the subject of Working Methods in Engineering, the project had as objective to develop skills in the areas of:

- Project management competences, including planning and project control;

- Write technical reports using an appropriate structure and technical language;

- Communicate in public effectively, using technical data to support the message;

- Communication. Namely developing the capacity to reach consensus, make decisions and manage conflicts.

Mathematics Laboratory I is inserted in the first semester of the first year of the Degree in Electrical Engineering - Electric Energy Systems' syllabus. It is a scientific subject of the
Mathematics area that intends to provide the skills for solving typical problems in engineering algebraically and numerically, using numerical methods (see, for example, [15] and [16]) and computer algebra systems.

As main goals of this subject, it is intended that students obtain reasoning and abstraction skills in order to:

- implement methods of algebraic and numeric resolution of problems;

- model engineering problems related to the degree mathematically;

- acquire critical sense, deductive reasoning, and graphic interpretation;

- be critical in the use of computer algebra software and numeric tools;

- do the integration between the nuclear subjects of Mathematics and Electrical Engineering.

As specific goals it is intended that a student should be able to:

- implement methodologies for solving problems using the algebraic and numeric tools (Matlab, Python and/or Matlab clone);

- understand the benefits and limitations of the algebraic and numeric tools (Matlab software, Python and/or Matlab clone);

- find and implement alternative methodologies to solve the problems;

- understand the several ways in which error can be introduced in the solution of the problem;

- solve equations of one variable numerically;

- use iterative methods in finding the solution sets of linear systems;

- evaluate derivatives and integrals numerically.

The subject contents were: the software introduction and error analysis; numerical methods for solving equations; methods for solving systems of equations and numerical differentiation and integration.

Mathematics I is a traditional one variable analysis subject (see, for example, [17] and [18]) with the following objectives:

- to characterize and manipulate real-valued functions in one variable;

- to use the techniques of differential calculus;

- to understand the notion of primitive of a function and to compute the primitive of functions using several methods;

- to understand the concept of definite integral and to use it to compute areas;

- to work with series of real numbers and with Taylor series, realizing its importance and its application to Engineering problems. 
Linear Algebra and Analytic Geometry aims to complement and consolidate the mathematics training of students gained during their academic life and develop the abstraction and reasoning ability of students. The subjects of ALGAN also aims the development of a mathematical language and the acquisition of critical spirit. It intends to give basic training in linear algebra and analytic geometry in order to enable the creation and solving mathematical models applied to Engineering (see [19]).

After attending the subject of ALGAN, students should be able to:

- perform basic operations on matrices, compute determinants and solve matrix equations;

- use matrices and determinants in the resolution and discussion of systems of linear equations;

- identify and generate vector fields and check linear dependence on the vectors; identify linear transformations and compute the associated matrices, eigenvalues, and eigenvectors;

- give analytical expressions for lines and planes; study intersections of lines and planes and identify geometrical spaces that satisfy some pre-determined conditions.

Teams of four students were formed in the beginning of the scholar year, in the classes of Mathematics Laboratory I (LMAT1). Students were invited to form the teams according to their preferences. There was a consensus among the students in the formation of the groups and there was no need for direct intervention of teachers in this process. Students without LMAT1, but attending one of the other three subjects, would not have an interest in participating in this project, as it needed a lot of support given in the classes of LMAT1. For these students, an alternative assessment was defined.

A total of eighty one students participated in this project. Each team received a project worksheet. The worksheets were not equal for all teams, but they proposed similar tasks.

\subsection{Planning for implementation of the tasks(weekly)}

An overview of the project milestones and tasks is shown in Table II. Task 1 included the study of a real-valued function of one real variable and solving some equations numerically. This was performed during the four weeks of October, the first month of the project.

A preliminary report was delivered at the end of the second week of November. This was followed by the task of solving systems of linear equations using algebraic and numerical methods. The preliminary report of this task was delivered at the end of the first week of December.

Finally, the problem involving sequences, Taylor series and symbolic and numerical integration was addressed in the second and third weeks of December. The preliminary report about this task was delivered at the end of the third week of December. The final report was delivered in the last week of December.

TABLE II. TASKS SCHEDULING (WEEKLY)

\begin{tabular}{|c|c|c|c|c|c|c|c|c|c|c|c|}
\hline \multirow[t]{2}{*}{ Tasks } & \multirow{2}{*}{\begin{tabular}{|l|} 
October \\
During \\
4 weeks
\end{tabular}} & \multicolumn{4}{|c|}{ November } & \multicolumn{4}{|c|}{ December } & \multicolumn{2}{|c|}{$\begin{array}{l}\text { January } \\
(2016)\end{array}$} \\
\hline & & $1^{\text {st }}$ & $2^{\text {nd }}$ & $3^{\text {rd }}$ & $4^{\text {th }}$ & $1^{\text {st }}$ & $2^{\text {nd }}$ & $3^{\text {rd }}$ & $4^{\text {th }}$ & $1^{\text {st }}$ & $2^{\text {nd }}$ \\
\hline $\begin{array}{c}\text { MATE 1 } \\
\text { Task1: Real-valued } \\
\text { function of a real variable }\end{array}$ & & & & & & & & & & & \\
\hline $\begin{array}{c}\text { LMAT 1 } \\
\text { Task1: Solve equations } \\
\text { numerically }\end{array}$ & & & & & & & & & & & \\
\hline $\begin{array}{c}\text { ALGAN } \\
\text { Task2:Solve systems of } \\
\text { linerar equations }\end{array}$ & & & & & & & & & & & \\
\hline $\begin{array}{c}\text { LMAT 1 } \\
\text { Task2:Solve systems of } \\
\text { linerar equations } \\
\text { numerically }\end{array}$ & & & & & & & & & & & \\
\hline $\begin{array}{c}\text { MATE } 1 \\
\text { Task3: Sequences/ } \\
\text { Series/Integration. }\end{array}$ & & & & & & & & & & & \\
\hline $\begin{array}{c}\text { LMAT1 } \\
\text { Task 3: Numerical } \\
\text { integration }\end{array}$ & & & & & & & & & & & \\
\hline $\begin{array}{c}\text { MTENG } \\
\text { Preparation of the Report }\end{array}$ & & & & & & & & & & & \\
\hline $\begin{array}{l}\text { Results/ display } \\
\text { resolution: task } 1\end{array}$ & & & & & & & & & & & \\
\hline $\begin{array}{l}\text { Results/display } \\
\text { resolution: task } 2\end{array}$ & & & & & & & & & & & \\
\hline $\begin{array}{l}\text { Results / display } \\
\text { resolution: task3 }\end{array}$ & & & & & & & & & & & \\
\hline Report delivery & & & & & & & & & & & \\
\hline Presentation/Discussion & & & & & & & & & & & \\
\hline
\end{tabular}

\subsection{Main tasks developed in the project}

The tasks proposed to the students include three groups of questions. The first task to be developed in this project involved real-valued functions of one real variable. The voltages across the capacitor component were studied. Thus, the charge/discharge of the capacitor, $q(\boldsymbol{t})$, in the RLC circuit (Fig. 1) was given. The analytic expression involved various exponential functions, for example,

$$
q(t)=\frac{57024\left(e^{\frac{\sqrt{43} t}{6}}+e^{-\frac{\sqrt{43} t}{6}}\right)+\frac{374112}{\sqrt{43}}\left(e^{\frac{43 t}{6}}-e^{-\frac{\sqrt{43} t}{6}}\right)}{6} e^{-\frac{7 t}{6}}
$$

$v_{C}(t)=\frac{q(t)}{C}$

$$
v_{L}(t)=L \frac{d i}{d t}
$$

$$
i=\frac{d q}{d t}
$$


The values for resistor, inductor, and capacitor are given, respectively, by

$$
R=7 \Omega L=3 H \quad C=2 F \text {. }
$$

Some questions concerning real-valued functions were addressed at the beginning:

$v_{L C}(t)=v_{L}(t)+v_{C}(t)$
After that, other two approximations of $I$ were calculated:

- on the one hand, approximating $l(x)$ by its Taylor polynomial of degree $n$ ( $n$ specified) and the value of the corresponding integral;

- on the other hand, using the trapezoidal and Simpson's rules.

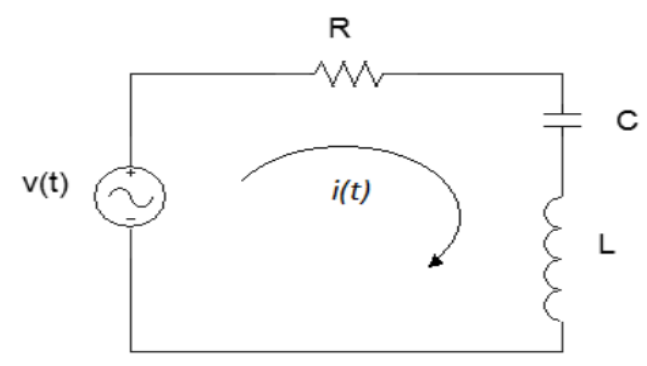

Figure 1: RLC circuit analyzed in Task 1.

$60 \%$

\subsection{5}

In the second task, an electrical circuit was given (see Figure 2). The circuit has different meshes. Using the Kirchhoff's laws for electrical circuits the students formulated the linear equations system to determine the currents in the circuit meshes.

A linear equations system was obtained. Then, the students were challenged to solve the system using algebraic methods such as Gaussian elimination and the Cramer's rule. After the use of these two algebraic methods, the students solved numerically the system of linear equations, using the iterative Jacobi and GaussSidel methods. Here, it was provided the opportunity of comparison between the results obtained from algebraic and numerical methods. Furthermore, this approach gave to the students the opportunity to compare the performance of the two numerical methods.

The last task concerned an integral calculus problem where symbolic integration was not possible. Therefore, the problem should be solved using Taylor series/polynomials, in order to obtain an approximation of the integral. In addition, the Simpson and trapezoidal rules were proposed to obtain the integral, using numerical quadrature. We focus that these tasks led to the simultaneous use of algebraic and numerical methods. The function was $l(x)=3 e^{-\frac{x^{2}}{4}}$ and the problem was to calculate the definite integral

$$
I=\int_{-2}^{2} l(x) d x
$$

At first, it was computed the Taylor series of $l$ and, next, the numerical series that allows computing the value of $I$. The convergence of the numerical series was also studied. 


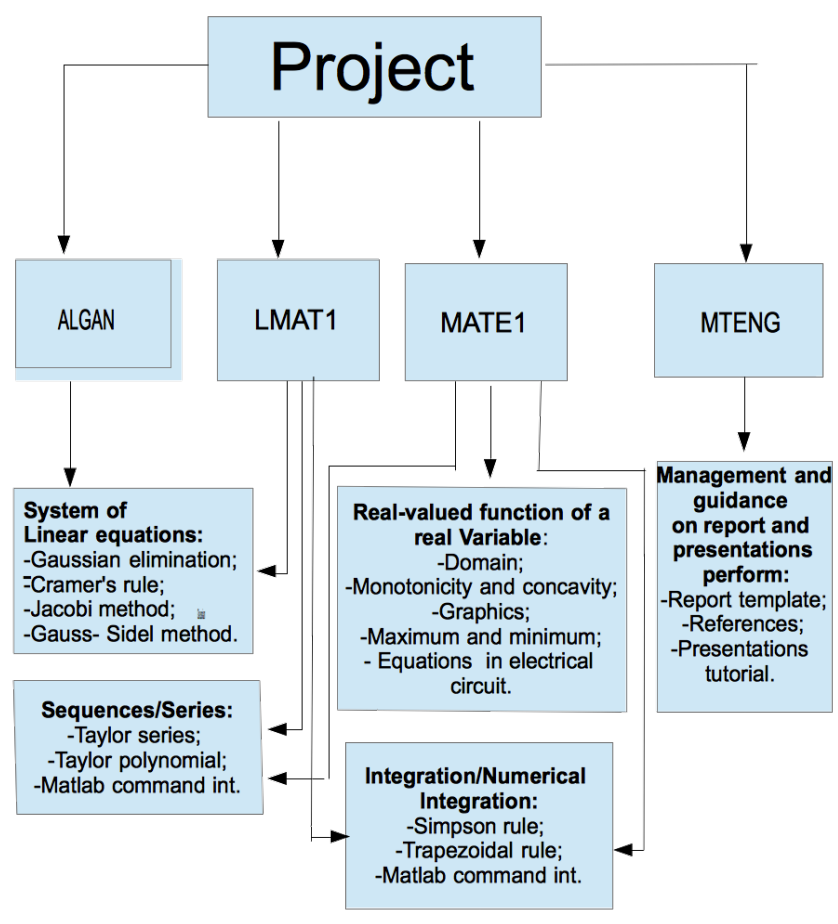

Figure 3: Topics and problems split into four different subjects

Prerequisite skills needed for the execution of the project are rather minimal. Students are required to have Mathematics education of secondary school. They should have some knowledge of basic electrical circuits. Some programming experience in Matlab or other higher-level language is helpful, but not required.

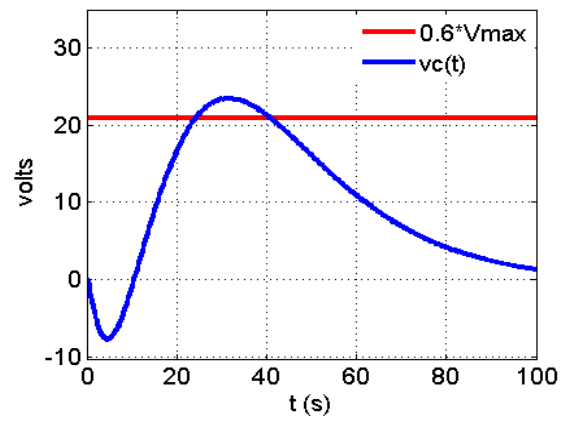

Figure 4: Graphic interpretation used in Task 1.

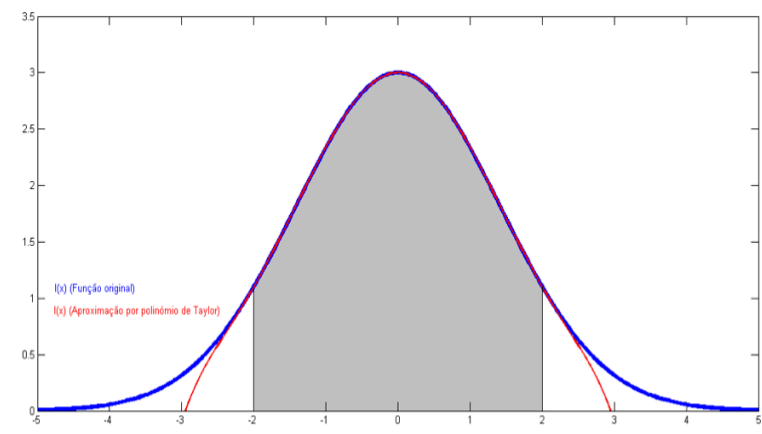

Figure 5: Numerical Integration.

We also highlight the use of the software MatLab@ and its symbolic and numeric toolboxes to support the study.
Furthermore, the graphical interpretation done by the students was improved by exploiting the graphical capabilities of the software. For instance, the graph presented in Fig. 4 (obtained with MatLab $($ ) ) provides a better insight of the equation to be solved numerically while the graphic presented in Fig. 5 provides an insight concerning the integral to be computed.

The students were faced with questions where it is necessary to choose between numeric and algebraic approaches. They should analyze the advantages and disadvantages of each other.

\subsection{Using the Moodle platform}

The use of a communication platform between teachers and students is essential for work coordination. There are several platforms available, but at ISEP it is implemented the Moodle platform, so we used it.

The Moodle platform was used for communication with students, providing supporting material and for the delivery of the final work. A proper space, accessible to all persons involved, was created in this platform to help the management of the process of delivery of the final work and its logistics.

\subsection{Transferability to other interdisciplinary projects}

This work emerged from a group of teachers' desire and the conviction that this kind of project brings significant gains for students. These are challenged to integrate the knowledge that is often presented to them in a disintegrated way giving the idea of knowledge fragmentation. But this type of work presents challenges, not only for students, teachers are also challenged to think globally, to overcome the limits of their subject, to integrate its specific knowledge with other areas and to coordinate their work with other teachers.

Everyone involved in this experience - teachers and students - shares the opinion that it should be repeated and, furthermore, there should be conditions to transfer it to other contexts and to other areas. In order to facilitate this transferability, we leave some practices that we consider essential to the success of future experiments in this context:

1. Project Planning - Phase essential to the success of the project. It should involve communication between teachers from different subjects in order to i) describe goals for each subject, ii) define tasks to be developed by students, iii) define moments and assessment tools and respective criteria, iv) prepare the project worksheet and v) set a plan of regular control meetings.

2. Project presentation to students - The project must be presented to students in detail, in the context of class, through the delivery of a project worksheet which should include i) project goals, ii) detailed tasks and deadlines iii) materials and tools necessary for the tasks implementation and iv) assessment moments, tools and respective criteria.

3. Teams definition - teams should be defined at the beginning of the work by the students.

4. Teachers monitoring - Teachers should accompany the group throughout the implementation of the project, acquainting themselves from problems that arise and supporting students to solve it. 
5. Coordination of the teaching staff - It is essential that teachers talk to students well-coordinated. For this purpose, project control meetings are very important.

6. Communication Platform for teachers / students - The use of a communication platform (in this case, the Moodle) seems to us essential to the success of the project.

7. Final Assessment - It is important that, in the end of the project, teachers and students have time to evaluate the process in which they were involved and reflect on the key lessons learned and define adjustments for the project replication.

8. The presence of all teachers in the oral presentation of projects - If we want to convey the message of interdisciplinarity, it is important that teachers are an example of commitment and networking.

\section{Results and Conclusions}

The Bologna reform brought new challenges for teachers and students of higher education. More student-centered teaching and crossing the frontiers of knowledge through interdisciplinary projects are examples of these new challenges [2, 3, 4]. In this paper, we intend to present the results of an interdisciplinary project carried out in an engineering school in the north of Portugal.

The results obtained by the participating students were generally positive. Students' involvement in the project was notorious. This involvement may be justified by the fact that, as Jacobs [5] and Chettiparamb [6] refer, interdisciplinary works provide the students with relevant, challenging and enjoyable learning experiences which may influence their degree of motivation and commitment in performing the tasks. In fact, the percentage of relative involvement of each student in the project was evaluated by his partners in the group. This information was asked to students in the moment of presentation and discussion of each team work.

As mentioned by Chettiparamb Interdisciplinary projects force students to integrate subjects that were apparently independent. The interdisciplinarity has implied a change of students' attitudes in the search for the development of integrated knowledge [6].

With this kind of challenge, students had the opportunity to develop a reflexive thought to overcome difficulties and, in this way, to develop knowledge and skills $[5,6]$.

In fact, many different skills have been developed by students throughout the execution of this project. As an example, we can point out the ability to work with others, to solve problems and conflicts, to integrate knowledge from different fields, to write a report using the citation rules and also the ability to make public presentations. As some authors have argued this kind of skills are very important for a future engineer that will be called to solve complex problems that require crossing boundaries $[7,11]$.

This type of work also puts great demands on the teachers involved in the project, particularly in terms of flexibility to integrate knowledge. Nevertheless, we think that the results in terms of benefits to the students justify all efforts that can be done to develop interdisciplinary work.
The results of the assessment of this project were used to evaluate students in the different subjects. The weight given to this project by each subject was different from subject to subjects. As each subject has established different goals to achieve with this interdisciplinary project, it has also defined its own assessment criteria as well as the weight of the project in the overall evaluation of the subject. This weight was $10 \%$ of the overall evaluation of the subject for ALGAN, 20\% for MATE1 and LMAT1, and 35\% for MTENG.

At the beginning of the oral presentation and discussion of the teamwork, each element of the team was asked to answer an auto assessment question. This question had to do with the perception that each element of the team had about the percentage of contribution of each element to all the work done.

In the report and in the oral presentation, students answered, in generally, correctly to what was asked. We can mention that the function studied on the first task was not an "academic" one (easy to analyse). They had to do research work and discuss it with the MATE1 teacher.

The exception was the last task (subsection 2.3) where students were asked to approach a definite integral by two different processes (numerical integration and using Taylor polynomials). The students' weakness was that they did not have the critical spirit to comment on the results obtained. For example, in one team of students, the results obtained by the two processes were very different. They did not realize that they should have compared the results and make conclusions.

By the end of the project, students' opinions regarding the challenge they had faced were assessed using a questionnaire. The students were asked to give their opinion about the nature of the project and its objectives (question 1); about their satisfaction concerning their personal involvement in the project (question 2); about the impact of the project in motivating them to learn mathematics related subjects (question 3); about the opinion on the overall assessment of the project (question 4), and about the project contribution to develop personal and team work skills (question 5). Students were also asked to provide general feedback on the project as well as to identify strengths and weaknesses. Except for this last open question, all the other questions were assessed using a Likert scale, being 1 "somewhat satisfied", and 5 "very satisfied". Thirty-six students answered the questionnaire. The average score was over 3.9 considering all the questions, reaching 4.1 in those questions where students assessed the objectives of the project, and 4.2 in the ones concerning students' opinion about the project contribution to the development of personal and team work skills (Fig. 6). As for strengths, students highlighted the relevance of the project for developing those skills and also for learning and consolidating mathematics-related subjects.

Although many of the respondent students did not mention any weakness, some pointed out the workload, and the short time period to develop the work as aspects to be improved in future editions. With that information in mind, we may conclude that students recognized the importance of this project not only to develop personal and teamwork skills but also to consolidate knowledge of the several subjects involved in the project. 


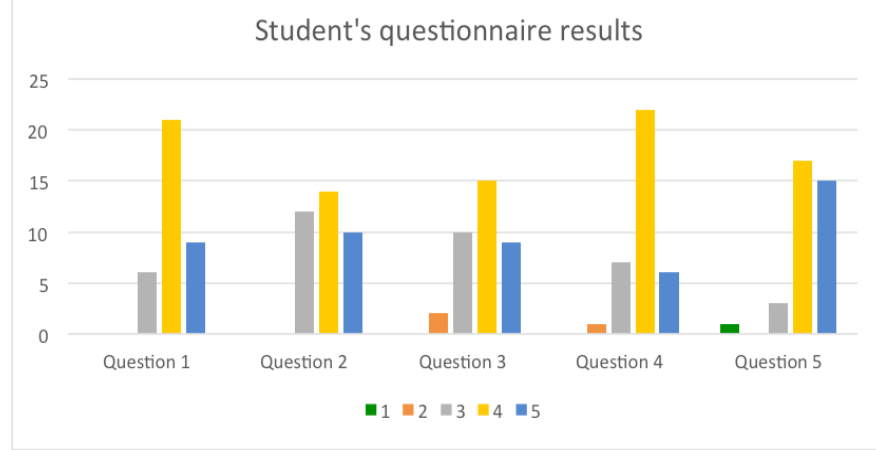

Figure 6: Students' questionnaire results

Despite the major benefits that this project has brought to the students, we are aware of the need to improve some aspects regarding planning and execution. At this stage, the coordination between the different involved teachers, the support provided to students during the project execution, and the management of the time students have dedicated to the project are the most challenging aspects and those with major impact on the success of the final project.

Taking into account the characteristics of this project and the context of the degree in which it is integrated (Electrical Engineer) it is important, in future experiences, to involve the subjects of Experimental Physics and Introduction to Electrotechnics. Their absence was one of the weaknesses of this experiment.

Other aspects to improve in new editions of the project are:

- to implement changes in the Moodle platform configuration to ensure a greater dynamic on the interaction between the members of each group, a greater dynamic on the interaction between students/teachers during the period of development of the work, and also to facilitate team work in online learning;

- to provide better conditions in online learning experiences, including team work will thus prepare students as effective members of teams in a virtual workplace of the future;

- to include a final report from every member identifying their contribution to the project;

- to provide some more class time for meetings because at the nowadays it is very hard for students to manage their schedules;

- to make the workload reasonable and the goals clear.

To conclude, it should be referred the intention of the authors to implement this project in other ISEP first degree courses (such as Electrical and Computer Engineering or Mechanical Engineering).

\section{Conflict of Interest}

The authors declare no conflict of interest.

\section{References}

[1] S. Abreu, A., Caldeira, A. Costa, T. Gomes, L. Roque, Interdisciplinary team work: applying working methods to a math project. In: Proceedings of the 2nd International Conference of the Portuguese Society for Engineering Education (CISPEE) (paper n.26).
IEEE Xplore Digital Library. ISBN 978-1-5090-3912-8 IEEE catalog number CFP16CIK-ART, 2016.

[2] M. Borrego, J. Bernhard, The Emergence of Engineering Education Research as an Internationally Connected Field of Inquiry. Journal of Engineering Education, 100(1), 14-47. https://doi.org/10.1002/j.21689830.2011.tb00003, 2011.

[3] R. Deem, K. H. Mok, K. H., L. Lucas, Transforming Higher Education in Whose Image? Exploring the Concept of the "World-Class" University in Europe and Asia. Higher Education Policy, 21(1), 83-97, 2008

[4] R. M. Lima, D. Carvalho, R. M. Sousa, A. C. Alves, Management of Interdisciplinary Project Approaches in Engineering Education: a Case Study. in First Ibero-American Symposium on Project Approaches in Engineering Education - PAEE2009 (D. Carvalho, N. v. HattumJanssen \& R. M. Lima), Guimarães - Portugal, 149-156, 2009

[5] W. J. Jacobs, Interdisciplinary trends in higher education. Palgrave Communications 1:15001 doi: 10.1057/palcomms, 2015.

[6] A. Chettiparamb, Inter-disciplinarity in teaching: probing urban studies. Journal for Education in the Built Environment, 6:1, 68-90, 2011.

[7] M. Borrego, S. Cutler, Constructive alignment of interdisciplinary graduate curriculum in engineering and science: an analysis of successful IGERT proposals. Journal of Engineering Education, 99(4), 355-369, 2010. https://doi.org/10.1002/j.2168-9830.2010.tb01068.

[8] S. G. Clark and R. L.Wallace, Integration and interdisciplinarity: concepts, frameworks, and education. Policy Sciences, 48, 233-255, 2015.

[9] S. Lélé and R. B. Norgaard, Practicing interdisciplinarity. BioScience, 55, 967, 2005.

[10] I.-B. Păvăloiu, I. Petrescu and C. Dragomirescu, Interdisciplinary project-based laboratory works. Procedia - Social and Behavioral Sciences, 180, 1145-1151, 2015.

[11] M. Borrego, L. K. Newswander, Characteristics of successful crossdisciplinary engineering education collaborations. Journal of Engineering Education, 97(2), 123-134, 2008 https://doi.org/10.1002/j.2168-9830.2008.tb00962

[12] G. P. Harrison, D. Ewen Macpherson, D. A. Williams, Promoting interdisciplinarity in engineering teaching. European Journal of Engineering Education, 32(3), 285-293, 2007. https://doi.org/10.1080/03043790701276775.

[13] European Commission/EACEA/Eurydice. The European Higher Education Area in 2015: Bologna Process Implementation Report. Luxembourg: Publications Office of the European Union, 2015.

[14] A. Veiga, A. Amaral, Survey on the implementation of the Bologna process in Portugal. Higher Education, 57(1), 57-69, 2009

[15] L. Richard, J. Burden, Douglas Faires. Numerical Analysis, 9th edition, Cengage Learning, 2011

[16] J. Stoer, R. Bulirsch, Introduction to Numerical Analysis. $3^{\text {a }}$.ed. Springer, 2002

[17] Larson, Hostetler and Edwards, Calculus, 8th edition, vol. 1, McGrawHill, 2011.

[18] J. Stewart, Calculus, 7th edition, vol. I, Cengage Learning, 2013.

[19] G. Strang, Introduction to Linear Algebra", 4th edition, WellesleyCambridge Press, 2010 